\title{
Determinants of COVID-19 Vaccine Acceptance in West Papua, Indonesia
}

\author{
Butet Agustarika*, Simon L Momot, Alva Cherry Mustamu (iD \\ Department of Nursing, HealthPolytechnic of Health Ministry, Sorong, Indonesia
}

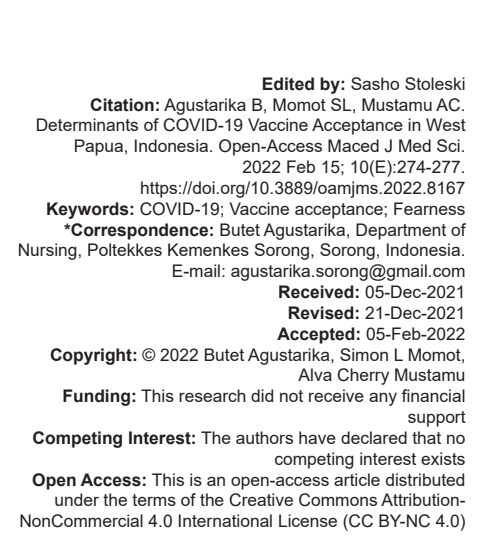

Introduction

The 2019 coronavirus disease pandemic (COVID-19) has spread across the world with millions of people infected and dying [1]. The pandemic is a significant threat to the public health system including the consequences of economic disasters around the world [2]. Meanwhile, most of the affected countries have developed successful response strategies and experienced significant improvement in recovery. A vaccine to prevent COVID-19 infection may be the best hope for ending the pandemic.

However, information on public perceptions of acceptance of the COVID-19 vaccine is not available. Numerous studies have identified several factors that are responsible for vaccine acceptance when a new vaccine is introduced [3], [4]. These include the safety and efficacy of vaccines, adverse health outcomes, misconceptions about the need for vaccination, lack of trust in the health system, and lack of public knowledge about vaccine-preventable diseases. Misinformation that leads to concerns and fear of vaccines can jeopardize public health in response to the current crisis.

Acceptance and demand for vaccines are complex and context specific, varying across time, place, and perceived behavioral nature of people [5]. Equitable, vaccination across all population groups is a challenge because of the complexity of human behavior that changes over time and space.

Several studies have investigated the prevalence of receiving the COVID-19 vaccine and its determinants [6], [7]. Another study in the United States reports that only $20 \%$ intend to refuse the COVID-19 vaccine [6]. Because vaccine acceptance is context specific and varies according to geography, culture, and sociodemographic, the study aims to understand the public's desire for the COVID-19 vaccine in West Papua, Indonesia.

\section{Materials and Methods}

Data were collected using an electronic questionnaire through Google Forms. The survey website address is distributed through Facebook, Instagram, and WhatsApp. At the end of December 2020, participants completed a questionnaire on Google Forms. Our sampling objective is to be representative of the general population in West Papua, Indonesia, by age, sex, education, occupation, and marital 
status. In addition, we are also looking for information about knowledge and concerns about receiving the COVID-19 vaccine. Participants are eligible if they are 18 years or over, can read Indonesian, and have a Gmail account with access to the internet through a computer or smartphone. This research is voluntary and the respondents do not receive any compensation.

Basic demographic information was collected as well as education, occupation, and marital status. In addition, we asked participants how strongly they agreed with the following statements (nominal scale; yes and no) knowledge about the COVID-19 vaccine (Cronbach's $\alpha=0.339$ ). Concerns about receiving vaccines; "Does the new variant of COVID-19 make you feel that the vaccine that is being given is in vain" (nominal scale; yes and no). Variables receiving the COVID-19 vaccine (nominal scale; yes and no). The Health Polytechnic of Health Ministry Sorong Research Ethics Board of the Ministry of Health of Sorong approved this research (protocol number DM.03.05/6/045/2020). Participants give consent before data collection.

This research is an open survey, where every an individual who gets a website address and is willing to participate in this research. Respondents who participated in this study were as many as 314 people. Descriptive statistics (frequency and percentage) were calculated for the demographic characteristics of the sample. In addition, the frequency and percentage, knowledge of vaccines, concerns, and acceptances of the COVID-19 vaccine were also calculated. Logistic regression analysis was used to assess the odds' ratio for demographic factors, knowledge of vaccines, and concerns with receiving COVID-19 vaccine. Data were analyzed using SPSS. This study was funded by the Health Polytechnic of Health Ministry Sorong. All authors have full access to all data in this study and are responsible for the decision to submit the manuscript.

\section{Results}

A total of 314 participants completed the survey with $171(54.5 \%)$ women aged 18-30 years as many as $73(23.2 \%)$ participants. Most of them have tertiary education, as many as $110(35 \%)$ participants, married as many as $264(81.1 \%)$, and became employees $117(37.3 \%)$ participants.

Of the 314 participants surveyed, 137 (43.6\%) said that they would receive the COVID-19 vaccine if recommended. As many as, $61.3 \%$ of women are willing to receive the vaccine compared to men. Participants aged $41-50(24.1 \%)$ were more willing to receive the COVID-19 vaccine than younger or older ages. Respondents with primary education such as elementary school $(35 \%)$ are more willing to receive vaccines than those with higher education. Respondents who work as employees $(35 \%)$ are more willing to receive vaccines than those who are not employees, unemployed, or retired. Married participants $(84.7 \%)$ are more willing to receive the vaccine than those who are not married or widows or widowers and are not married. Participants who had less knowledge about COVID-19 (56.2\%) were more willing to receive the vaccine than those with good knowledge. As many as, $56.2 \%$ of respondents who are not worried about the COVID-19 vaccine are more willing to receive the vaccine. Data is presented in Table 1.

\section{Multivariable analysis}

The multivariable regression model describes cases of vaccine acceptance. Gender (odds ratio [OR] $=1,475 ; 95 \%$ confidence interval $[\mathrm{Cl}]=0.903-2.408 ; \mathrm{P}>$ $0.05)$, age $(\mathrm{OR}=1,003 ; 95 \% \mathrm{Cl}=0.852-1,180 ; \mathrm{P}>0.05)$, education level $(\mathrm{OR}=0.635 ; 95 \% \mathrm{Cl}=0.434-0.927 ; \mathrm{P}$ $<0.05$ ), occupation (OR $=1.025 ; 95 \% \mathrm{Cl}=0.861-1.221$; $\mathrm{P}>0.05)$, marital status (OR $=0.945 ; 95 \% \mathrm{Cl}=0.660$ 1353; $\mathrm{P}<0.05)$, level of knowledge $(\mathrm{OR}=2.064 ; 95 \% \mathrm{Cl}=$ $1,133-3,762 ; \mathrm{P}<0.05)$ and fearness $(\mathrm{OR}=0.602 ; 95 \% \mathrm{Cl}=$ $0.379-0.955 ; P<0.05)$. So in this study, we found that level of education, knowledge, and fear are the main predictive factors for vaccine acceptance. Data is presented in Table 2.

\section{Discussion}

We found that education level, knowledge, and fear were the main predictive factors for vaccine acceptance. This is in accordance with several previous studies [8], [9] which states that the level of education and knowledge is one of the most important factors in determining someone to receive the vaccine.

We are of the view that COVID-19 is a newly discovered disease in Wuhan, China, about a year ago. Care for this disease is not yet clear because the specific drug to treat this disease is not yet available. Then, come the vaccine which is currently starting to circulate in the world, including Indonesia. This is definitely a cause for concern among people public due to lack of clear and reliable information. In addition, the confusion of information circulating causes increasing fear among the public.

As many COVID-19 vaccines are being developed [10] based on the disease variants that continue to emerge to prevent and enhance immunity, it is important that we understand the exact causes of fear and doubt that exist in society. This basis will be used for the development of evidence-based interventions so that people are willing to accept the vaccine that will be given, not out of compulsion (Schaffer DeRoo et al., 2020).

The education level, knowledge level, and fear have a very close relationship in regulating a person's behavior, including in receiving vaccines. The level of 
education makes a person more agile in using the media to access information. When receiving information, knowledge will increase. When the information obtained is invalid, behavioral concerns will arise.

In this study, we found that participants became concerned about vaccination due to a new variant of COVID-19 so that vaccinations were in vain. This was stated in several sources which stated there was a new variant of COVID-19 [11], [12]. In addition, several studies have found that many Phase 3 studies fail due to the misidentification of doses and thus, doubt the safety and efficacy of the vaccine [13].

Table 1: Demographic characteristics of the survey participants

\begin{tabular}{lll}
\hline Variable & Total $(\mathrm{n}=314), \mathrm{n}(\%)$ & COVID-19 vaccine acceptance, $\mathrm{n}(\%)$ \\
\hline Gender & & \\
Male & $143(45.5)$ & $53(38.7)$ \\
Female & $171(54.5)$ & $84(61.3)$ \\
Age & & \\
18-30 & $73(23.2)$ & $27(19.7)$ \\
$31-40$ & $60(19.1)$ & $33(21.2)$ \\
$41-50$ & $63(20.1)$ & $26(19)$ \\
$51-60$ & $59(18.8)$ & $22(16.1)$ \\
$>61$ & $59(18.8)$ & $48(35)$ \\
Education & & $47(34.3)$ \\
Primary & $100(31.8)$ & $42(30.7)$ \\
Secondary & $104(33.1)$ & \\
Tertiary & $110(35 \%)$ & $48(35)$ \\
Occupation & & $41(29.9)$ \\
Employed & $117(37.3)$ & $9(6.6)$ \\
Non-employed & $92(29.3)$ & $7(5.1)$ \\
Retired & $30(9.6)$ & $32(23.4)$ \\
Students & $18(5.7)$ & \\
Housewives & $57(18.2)$ & $3(2.2)$ \\
Marital status & & $116(84.7)$ \\
Not married & $5(1,6)$ & $4(2.9)$ \\
Married & $264(81.1)$ & $14(10.2)$ \\
Widow & $10(3.2)$ & \\
Single & $35(11.1)$ & $77(56.2)$ \\
Knowledge & & $60(43.8)$ \\
Less & $188(59.9)$ & $77(56.2)$ \\
Good & $126(40.1)$ & $60(43.8)$ \\
Fearness & $156(49.7)$ & \\
No & $158(50.3)$ & \\
Yes & & \\
\hline
\end{tabular}

The authors point out that a planned Phase 3 trial of the severe acute respiratory syndrome corona virus type 2 messenger ribonucleic acid vaccine is imminent. This trial will require thousands of subjects to ensure vaccine safety and to demonstrate statistically strong efficacy in preventing COVID-19. Efficacy could only be determined if there was a match between the locations of the vaccinated participants and pandemic hotspots. The uncertainty about the expected effectiveness profile also drives complexity; the observed profile for other viral vaccines suggests that efficacy against severe COVID-19 may be higher than efficacy against mild disease [14].

However, what must be paid attention is the information circulating in the community must be valid so as not to cause speculation and uproar of information to worry that it will result in not receiving the vaccine in

Table 2: Summary of logistic regression analysis for variables predicting COVID-19 vaccine acceptance $(n=314)$

\begin{tabular}{lllll}
\hline Predictor & OR & SE & $95 \% \mathrm{Cl}$ & $\mathrm{p}$-value \\
\hline Gender & 1.475 & 0.250 & $0.903-2.408$ & 0.120 \\
Age & 1.003 & 0.083 & $0.852-1.180$ & 0.974 \\
Education & 0.635 & 0.183 & $0.434-0.927$ & 0.019 \\
Occupation & 1.025 & 0.089 & $0.861-1.221$ & 0.777 \\
Marital status & 0.945 & 0.193 & $0.660-1.353$ & 0.757 \\
Knowledge & 2.064 & 0,306 & $1.133-3.762$ & 0.018 \\
Fearness & 0.602 & 0.236 & $0.379-0.955$ & 0.031 \\
\hline
\end{tabular}

society. Providing vaccine information and education have not been shown to be a consistently effective strategy for increasing vaccine uptake. The personal decision-making process involves indirect social and emotional pressures.

\section{Conclusions}

This study has several limitations. The distribution of respondents in each area is unequal and may limit the generalizability of results. In conclusion, the biggest predictors of vaccine acceptance are education, knowledge, and concern. Further, studies to identify key actionable factors are needed to develop new effective interventions to promote information stability to increase interest in immunization acceptance.

\section{Declarations}

\section{Ethics approval and consent to participate}

In agreement with the Declaration of Helsinki, the proposal was approved by the Institutional Review Board Health Polytechnic of Health Ministry Sorong Research Ethics Board of the Ministry of Health of Sorong (protocol number DM.03.05/6/045/2020).

\section{Availability of data and material}

The datasets used and/or analyzed during the present study are available from the corresponding author on reasonable request.

\section{Authors' Contributions}

$\mathrm{BA}$ and $\mathrm{ACM}$ are involved in the conception and design of the study, performed data analysis and interpretation, wrote the manuscript, supervised the development of work, and helped in data interpretation and manuscript evaluation. ACM helped to evaluate and edit the manuscript. BAacted as the corresponding author. All authors read and approved the final manuscript.

\section{Acknowledgments}

We are appreciative to Health Polytechnic of Health Ministry Sorong, Indonesia, that participated in the research. 


\section{References}

1. Malik AA, McFadden SM, Elharake J, Omer SB. Determinants of COVID-19 vaccine acceptance in the US. EClinicalMedicine. 2020;26:100495. https://doi.org/10.1016/j.eclinm.2020.100495 PMid:32838242

2. Chakraborty C, Sharma AR, Bhattacharya M, Sharma G, Lee SS. The 2019 novel Coronavirus disease (COVID-19) pandemic: A zoonotic prospective. Asian Pac J Trop Med. 2020;13(6):242. Available from: https://www.apjtm.org/article. asp?issn=1995-7645; year=2020; volume $=13$;issue $=6 ;$ spage $=2$ 42 ; epage $=246$; ;ulast $=$ Chakraborty; type $=0$ [Last accessed on 2021 Jan 11]

3. Xiao X, Wong RM. Vaccine hesitancy and perceived behavioral control: A meta-analysis. Vaccine. 2020;38(33):5131-8. https:// doi.org/10.1016/j.vaccine.2020.04.076

PMid:32409135

4. Gidengil CA, Parker AM, Zikmund-Fisher BJ. Trends in risk perceptions and vaccination intentions: A longitudinal study of the first year of the H1N1 pandemic. Am J Public Health. 2012;102(4):672-9. https://doi.org/10.2105/AJPH.2011.300407 PMid:22397349

5. Habersaat KB, Jackson C. Understanding vaccine acceptance and demand-and ways to increase them. Bundesgesundheitsblatt Gesundheitsforschung Gesundheitsschutz. 2020;63(1):32-9. https://doi.org/10.1007/s00103-019-03063-0

PMid:31802154

6. Thunstrom L, Ashworth M, Finnoff D, Newbold S. Hesitancy Towards a COVID-19 Vaccine and Prospects for Herd Immunity, Report No. ID 3593098. Rochester, NY: Social Science Research Network; 2020. Available from: https://www.papers. ssrn.com/abstract=3593098 [Last accessed on 2021 Jan 11].

7. Fu C, Wei Z, Pei S, Li S, Sun X, Liu P. Acceptance and Preference for COVID-19 Vaccination in Health-Care Workers (HCWs), medRxiv; 2020. Available from: https://www.medrxiv. org/content/10.1101/2020.04.09.20060103v1 [Last accessed on 2021 Jan 11].

8. Kara SS, Polat M, Yayla BC, Demirdag TB, Tapisiz A, Tezer H, et al. Parental vaccine knowledge and behaviours: A survey of Turkish families. East Mediterr Health J. 2018;24(5):451-8. https://doi.org/10.26719/2018.24.5.451

PMid:30043964

9. Awadh AI, Hassali MA, Al-Lela OQ, Bux SH, Elkalmi RM, Hadi H. Does an educational intervention improve parents' knowledge about immunization? Experience from Malaysia. BMC Pediatr. 2014;14(1):254. https://doi.org/10.1186/1471-2431-14-254 PMid:25284603

10. DeRoo SS, Pudalov NJ, Fu LY. Planning for a COVID-19 vaccination program. JAMA. 2020;323(24):2458-9. https://doi. org/10.1001/jama.2020.8711

PMid:32421155

11. BBC. Varian Baru Virus Corona Yang Menginfeksi Anak Muda Ditemukan di Afrika Selatan, BBC News Indonesia; 2021. Available from: https://www.bbc.com/indonesia/dunia-55420197 [Last accessed on 2021 Jan 11].

12. Baric RS. Emergence of a highly Fit SARS-CoV-2 variant. N Engl J Med. 2020;383(27):2684-6. https://doi.org/10.1056/ NEJMcibr2032888 PMid:33326716

13. Musuamba FT, Manolis E, Holford N, Cheung SYA, Friberg LE, Ogungbenro $\mathrm{K}$, et al. Advanced methods for dose and regimen finding during drug development: Summary of the EMA/EFPIA workshop on dose finding (London 4-5 December 2014). CPT Pharmacometrics Syst Pharmacol. 2017;6(7):418-29. https:// doi.org/10.1002/psp4.12196

PMid:28722322

14. Heaton PM. The COVID-19 vaccine-development multiverse. N Engl J Med. 2020;383(20):1986-8. https://doi.org/10.1056/ NEJMe2025111

PMid:32663910 